\title{
Study on Dynamic Characteristics of Rubber-Red Clay Mixtures
}

\author{
Kaisheng Chen $\mathbb{D}$, ${ }^{1}$ Qinqin Wang $\mathbb{D},^{2}$ Dipu Luo $\mathbb{D}^{1},{ }^{1}$ Bo Zhou $\mathbb{D},{ }^{1}$ and Kun Zhang $\mathbb{D}^{1}$ \\ ${ }^{1}$ Civil Engineering College, Guizhou University, Guiyang 550025, Guizhou, China \\ ${ }^{2}$ Qiannan Traffic Test and Detection Co., Ltd., Douyun 558000, Guizhou, China
}

Correspondence should be addressed to Qinqin Wang; wangqinqin750402@163.com

Received 19 August 2020; Revised 5 October 2020; Accepted 24 October 2020; Published 6 November 2020

Academic Editor: Veronica Calado

Copyright $\odot 2020$ Kaisheng Chen et al. This is an open access article distributed under the Creative Commons Attribution License, which permits unrestricted use, distribution, and reproduction in any medium, provided the original work is properly cited.

Rubber powder formed from discarded tire rubber is mixed with red clay to form a rubber-red clay mixture. The dynamic triaxial test was carried out on the mixtures under different conditions. The effects of rubber content, rubber particle size, moisture content of mixed soil, compactness, confining pressure, and vibration frequency on shear strain relation, dynamic shear modulus, and damping ratio of the mixture were investigated. The results show that under the same dynamic strain, the dynamic shear stress-strain curve of rubber mixed soil decreases with the increase in rubber particle content and moisture content and decrease in rubber particle size. On the other hand, it increases with the increase in compactness, confining pressure, and vibration frequency, and as the dynamic strain increases, the $\tau_{d}-\gamma_{d}$ curve becomes more nonlinear. In addition, with the increase in the rubber particle content, the dynamic shear modulus decreased while the damping ratio increased. When the content was $2 \%$, the change was fastest. After continued addition, it gradually became stable, and when the decrease in rubber particle size also shows the same pattern, $2.00 \mathrm{~mm}$ rubber-red clay mixture shows better structure. The water content has great influence on dynamic shear modulus and damping ratio of rubber-red clay mixtures. With the increase in compactness, confining pressure, and vibration frequency, the interaction between mixed soil particles was enhanced, the dynamic shear modulus increased, and the damping ratio decreased.

\section{Introduction}

How to deal with the black pollution caused by waste tires is a big problem that plagues the engineering community. In order to save resources and protect the environment and find new ways to reuse waste tire rubber, domestic and foreign scholars have added rubber particles to asphalt, concrete, and soil and proposed a new geotechnical treatment method for waste tire rubber. Because the formed rubber mixture has good mechanical, thermal insulation, and water permeability properties, it has been widely used in road engineering, earth-rock dams, retaining walls, and foundations [1-10].

At present, there are few studies on the mechanical properties and related laws of rubber-improved soil. Tiwari et al. [11] performed the compaction test on rubber-clay mixture. It is found that as the amount of rubber powder increased, the maximum dry density of the sample decreased, and the optimal moisture content did not change significantly. Li and Zhang [12] added rubber to loess and conducted an experiment on the mixture. It was found that when the amount of rubber powder was less than $20 \%$, the compaction characteristics of the mixed soil were similar to that of loess, and while the amount is greater than $40 \%$, the compaction characteristics were similar to noncohesive soils. The relationship between the maximum dry density and optimum water content could be expressed by power function. After mixing the tire fragments with sand and silt, Tatlisoz and Okur et al. $[13,14]$ found the shear strength of the mixed sand was improved to a certain extent, while the shear strength of the mixed silt was reduced after rubber was added to the silt. Through the direct shear test, Gunaydin et al. [15] found the cohesive force increases with the increase in the content when the rubber content is below $40 \%$, and the change trend of the internal friction angle is the opposite. Feng et al. [16-19] studied the influence of rubber powder content on the dynamic shear modulus and damping ratio of rubber-sand mixture under different 
conditions through resonance column experiments and proposed an empirical model for calculating the dynamic parameters of rubber-sand mixture. Kermani et al. [20] studied the dynamic shear modulus and damping ratio of rubber-sand mixture with different rubber content and different confining pressures through cyclic triaxial tests and proposed the normalization equation between the dynamic shear modulus and dynamic strain. Shang et al. [21] and Liu et al. [22] studied the laws of dynamic shear modulus and dynamic shear strain of rubber-sand mixture with different contents. Li et al. [23] studied the dynamic strength, dynamic modulus, and damping ratio of rubber-sand mixtures with different powder contents by dynamic triaxial tests. Hu et al. [24] found that as the amount of rubber powder increased, the dynamic elastic modulus and dynamic shear modulus of rubber-loess mixture decreased, but the damping ratio increased instead.

Based on the research status, the research on rubber-soil mixture mainly focused on sandy soil, and there were few reports on the dynamic characteristics of rubber-clay mixture. However, due to the different types of soil, the properties of mixtures are also quite different. In view of this, the dynamic shear stress-shear strain, dynamic shear modulus, and damping ratio of rubber-red clay mixtures under different factors such as powder content, particle size, compaction, and moisture content have been studied through indoor dynamic triaxial tests. A constitutive model suitable for dynamic shear modulus, damping ratio, and shear strain of rubber-red clay is proposed. The research results have certain academic and application value and provide a new idea for the reuse of waste tires.

\section{Dynamic Triaxial Test}

2.1. Test Method. The test uses the SDT-20 dynamic triaxial produced by Xi'an Lichuang Material Testing Technology Co., Ltd. (see Figure 1) and adopts a stepwise incremental cyclic loading test method. 10 cycles of loads having various amplitudes are applied to the samples. The fifth vibration of each level of load is taken as the test result. Sine wave was selected as the carrier wave shape, the sample size was $39.1 \mathrm{~mm}$ in diameter and $80 \mathrm{~mm}$ in height, the consolidation method was isotropic consolidation, and the consolidation ratio is 1.0. The confining pressure is $50 \mathrm{kPa}, 100 \mathrm{kPa}$, $150 \mathrm{kPa}$, and $200 \mathrm{kPa}$. In addition, the vibration frequency is $1 \mathrm{~Hz}, 2 \mathrm{~Hz}$, and $4 \mathrm{~Hz}$, respectively. The undrained dynamic triaxial test was carried out after the test parameters are determined.

2.2. Test Materials and Sample Preparation. The soil samples used in this paper were taken from the foundation pit of Huashi Road on the west side of Guizhou University. It is brown-plastic red clay with good gradation and compact structure. The basic physical indexes of red clay are shown in Table 1 . The rubber is mechanically crushed from waste tires, and the particle sizes of the rubber powders were $2.00 \mathrm{~mm}$, $0.85 \mathrm{~mm}$, and $0.25 \mathrm{~mm}$, as shown in Figure 2 .
After the red clay was air-dried and crushed, it is passed through a $2 \mathrm{~mm}$ sieve, and $0 \%-10 \%$ mixed soil is prepared according to the mass ratio of rubber powder and dry soil, such as $10 \%$ rubber mixed soil; that is, rubber powder quality: dry soil quality $=1: 9$. It can be seen from Table 2 that with the increase in rubber powder content, the optimal moisture content and maximum dry density of rubber-red clay mixture decrease. In the standard test mold ( $\Phi$ $39.1 \times 80 \mathrm{~mm}$ ), static compaction was used to prepare samples with different rubber powder contents, different rubber powder particle sizes, different moisture contents, and different compaction degrees (Table 3). The sample preparation process is briefly summarized as follows: (a) Calculate the sample mass according to equation (1). It is difficult to form the sample after the rubber powder content exceeds $10 \%$. The maximum rubber powder content is $10 \%$.

$$
m_{\text {sample }}=k \rho_{d \max }(1+\omega) V,
$$

where $m_{\text {sample }}$ is the mass of the sample, $k$ is the degree of compaction, $\rho_{d \max }$ is the maximum dry density, $\omega$ is the moisture content, and $V$ is the volume of the sample mold. (b) Put the abovementioned mixed soil into a standard test mold; the mixed soil was compacted under static pressure and roughens each layer. (c) The samples were put into a curing box for one day to make the moisture content of each part of the sample uniform.

\section{Dynamic Characteristic Parameter Calculation Method}

3.1. Dynamic Shear Stress-Shear Strain. The dynamic triaxial test can collect dynamic shear stress and shear strain through multistage loading dynamic load. According to the hysteresis loop of shear stress and strain, the dynamic shear stressstrain backbone curve can be drawn. The backbone curve reflects the nonlinearity between dynamic shear stress and strain. According to the Hardin-Drnevich hyperbolic model [25-28], the relationship between dynamic shear stress and shear strain can be expressed as follows:

$$
\tau_{d}=\frac{\gamma_{d}}{a+b \gamma_{d}}
$$

where $\tau_{d}$ is the dynamic shear stress, $\gamma_{d}$ is the dynamic shear strain, and $a$ and $b$ are the soil properties parameters.

3.2. Dynamic Shear Modulus. According to the shear characteristics of soil under cyclic loading, the dynamic shear modulus when the dynamic shear strain tends to 0 is defined as the maximum dynamic shear modulus $\left(G_{\max }\right)$. According to the relationship between dynamic shear modulus and the dynamic shear strain, the shear modulus ratio can be expressed by the following equation [29]:

$$
G=\frac{G \max }{1+\left(\gamma / \gamma_{r}\right)}
$$

where $G$ is the dynamic shear modulus, $G_{\max }$ is the maximum shear strain, $\gamma$ is the dynamic shear strain, and $\gamma_{r}$ is the reference shear strain. 


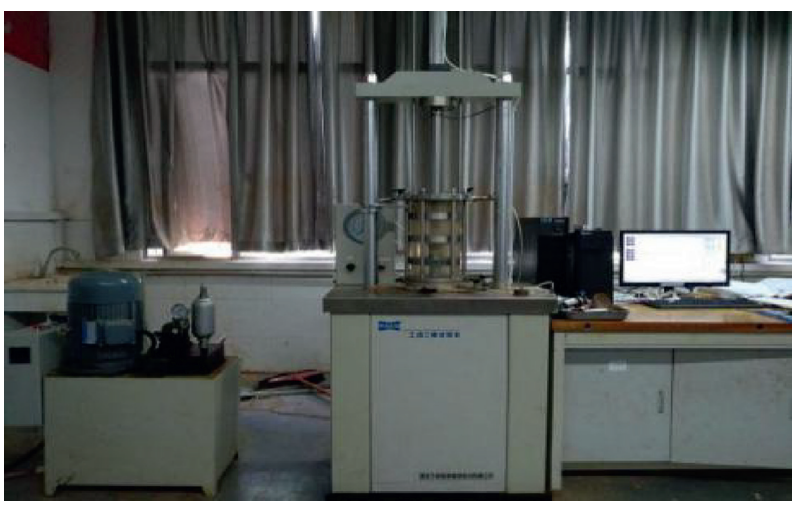

FIgURE 1: Soil triaxial testing machine.

TABLE 1: Basic physical indicators of red clay.

\begin{tabular}{lcccc}
\hline Plastic limit (\%) & Liquid limit (\%) & Plasticity index & \multicolumn{3}{c}{ Particle composition (\%) } \\
$0.075 \sim 0.002 \mathrm{~mm}$ & $<0.002 \mathrm{~mm}$ \\
\hline 24.83 & 43.60 & 18.4 & 19.36 & 64.30 \\
\hline
\end{tabular}

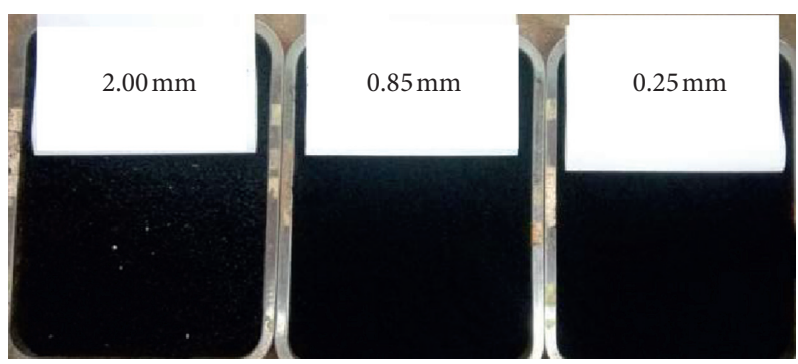

FIgURE 2: Different particle size rubber particles.

TABLE 2: Results of rubber-red clay compaction experiment.

\begin{tabular}{lcc}
\hline Rubber powder content $(\%)$ & Optimal moisture content $(\%)$ & Maximum dry density $\left(\mathrm{g} / \mathrm{cm}^{3}\right)$ \\
\hline 0 & 24.26 & 1.633 \\
2 & 23.95 & 1.605 \\
4 & 22.48 & 1.581 \\
6 & 22.08 & 1.548 \\
8 & 21.95 & 1.522 \\
10 & 21.50 & 1.503 \\
\hline
\end{tabular}

TABLE 3: Rubber mixed soil cooperation scheme.

\begin{tabular}{|c|c|c|c|}
\hline Rubber powder content (\%) & Rubber particle size (mm) & Moisture content (\%) & Compactness (\%) \\
\hline $0 \sim 10$ & 0.85 & $24.83,23.95,22.48,22.08,21.95,21.5$ & 90 \\
\hline \multirow{3}{*}{6} & 2.00 & & \\
\hline & 0.85 & 24.83 & 90 \\
\hline & 0.25 & & \\
\hline \multirow{3}{*}{6} & & 22 & \\
\hline & 0.85 & 24.83 & 90 \\
\hline & & 28 & \\
\hline \multirow{3}{*}{6} & & & 85 \\
\hline & 0.85 & 24.83 & 90 \\
\hline & & & 96 \\
\hline
\end{tabular}


3.3. Damping Ratio. According to the elastoplastic theory, the damping ratio is defined as the ratio of the hysteresis loop to the area of the triangle in Figure 3:

$$
\lambda=\frac{1}{4 \pi} \frac{A_{s}}{A_{t}},
$$

where $\lambda$ is the damping ratio, $A_{t}$ is the area of the hysteresis loop, and $A_{s}$ is the area of the triangle in the shaded area.

The Chen et al. model [30] describes the damping ratio as follows:

$$
\lambda=\lambda_{\min }+\lambda 0\left(1-\frac{G}{G_{\max }}\right)^{n} .
$$

Introduce the minimum damping ratio $\lambda_{\min }$, modify the damping ratio formula of the Chen et al. model, and obtain the empirical model:

$$
\lambda=\lambda_{\min }+\lambda_{0}\left(1-\frac{1}{1+\left(\gamma / \gamma_{a}\right)}\right)^{n},
$$

where $\lambda_{\min }$ is the minimum damping ratio, which is the fitting parameter, $\gamma_{a}$ is the reference shear strain, which is a fitting parameter, and $\lambda_{0}$ and $n$ are the fitting parameters.

\section{Results and Discussions}

4.1. Description of Test Phenomenon. In this test, there are two main failure types of the rubber-red clay mixtures. When the rubber powder content is low or the moisture content is high, it shows a bulging failure (Figure 4). In addition, when the rubber powder content is high or moisture content is high, the sample shows shear failure (Figure 5). The reason is that the red clay particles are small, the specific surface area is large, and there is interaction between the particles. When rubber particles are added into red clay, the degree of bonding between the soil is reduced. While the moisture content decreases, the cementation between the soil particles weakens, so the two show obvious shear phenomena. On the other hand, when the moisture content increases, the interaction between soil and water increases, and the bonding force becomes larger. When the amount of rubber powder decreases, the pores become smaller. Therefore, the samples show a bulging damage in both cases.

\subsection{Dynamic Shear Stress-Shear Strain Relationship Curve.} Figure 6 shows the dynamic shear stress and strain curves of rubber-red clay mixture under different rubber powder contents, different rubber powder particle sizes, different moisture contents, different compactions, different confining pressures, and different vibration frequencies. It can be seen as the backbone curve of rubber-red clay mixture. The curve could be divided into two stages. When the dynamic shear strain is small, the curve grows linearly and is in the elastic stage. When the dynamic shear strain continues to increase, the curve tends to be smooth and in the elastic- plastic stage. It can also be seen that the skeleton curve of the mixture is hyperbolic, which was same as the Hardin-Drnevich hyperbolic model of equation (2). For example, the mixture with the rubber powder content is $6 \%$, the particle size is $0.85 \mathrm{~mm}$, the moisture content is $24.83 \%$, and the compaction degree is 90 . The confining pressure was $100 \mathrm{kPa}$ and vibration frequency was $1 \mathrm{~Hz}$, and they are fitted using equation (2); the experimental data have a high degree of agreement with the model, so the Hardin-Drnevich model can be used to describe the dynamic shear stress and strain curve of the rubber-red clay mixture.

In Figure 6(a), with the increase in rubber powder content, the backbone curve gradually decreases, and the curve changes from strong hardening to weak hardening. The backbone curve of mixture continues decreasing, but the decreasing rate kept becoming small and the curves are getting closer to each other. Taking dynamic shear strain $\gamma_{d}=0.6 \%$ as an example (the same below), the relative change of dynamic shear stress in the process of increasing the rubber content from $0 \%$ to $10 \%$ is when the content is from $0 \%$ to $2 \%$, the difference between the dynamic shear stress was largest, reaching $6.43 \mathrm{kPa}$, and then it became stable and shows a downward trend; that is, the relative dynamic shear stress drops from $3.71 \mathrm{kPa}$ to $2.81 \mathrm{kPa}$. In Figure 6(b), as the rubber particle size decreases, the rubberred clay backbone curve appears weakly hardened. When the mesh size is reduced from $2.00 \mathrm{~mm}$ to $0.25 \mathrm{~mm}$, the backbone curve becomes smoother. The smaller the rubber powder particle size, the more obvious the impact on the dynamic shear stress. When it is reduced from $2.00 \mathrm{~mm}$ to $0.85 \mathrm{~mm}$, the dynamic shear stress drops by $4.07 \mathrm{kPa}$; when it is reduced from $0.85 \mathrm{~mm}$ to $0.25 \mathrm{~mm}$, the dynamic shear stress drops by $5.67 \mathrm{kPa}$. In Figure 6(c), as the water content increases, the dynamic shear stress gradually decreases. When the moisture content increases from $22 \%$ to the optimal moisture content, the dynamic shear stress drops by $6.29 \mathrm{kPa}$. When the moisture content increases from the optimal moisture content to $28 \%$, the dynamic shear stress drops by $7.97 \mathrm{kPa}$. The influence of moisture content on the wet side of the optimal moisture content on the dynamic shear stress-shear strain is greater than that on the dry side.

As shown in Figures 6(d)-6(f), with the increase in compaction, confining pressure, and vibration frequency, the linear characteristics of the rubber-soil backbone curve increase. The greater the degree of compaction was, the greater the amplitude of the dynamic shear stress was. When the degree of compaction increases from $85 \%$ to $90 \%$ and from $90 \%$ to $96 \%$, the dynamic shear stress increases by $4.49 \mathrm{kPa}$ and $6.01 \mathrm{kPa}$, respectively. Confining pressure is the most important factor affected the dynamic shear stressshear strain curve. When the confining pressure increases from $50 \mathrm{kPa}$ to $100 \mathrm{kPa}$, the dynamic shear stress increases most significantly, reaching $16.19 \mathrm{kPa}$, and then the increase rate gradually decreases. The vibration frequency has the smallest effect on the dynamic shear stress-shear strain curve. The frequency increases from $1 \mathrm{~Hz}$ to $2 \mathrm{~Hz}$ and from $2 \mathrm{~Hz}$ to $4 \mathrm{~Hz}$, and the dynamic shear stress increases by $2.26 \mathrm{kPa}$ and $3.98 \mathrm{kPa}$; that is, as the vibration frequency increases, the increase in the dynamic shear stress is smaller. 


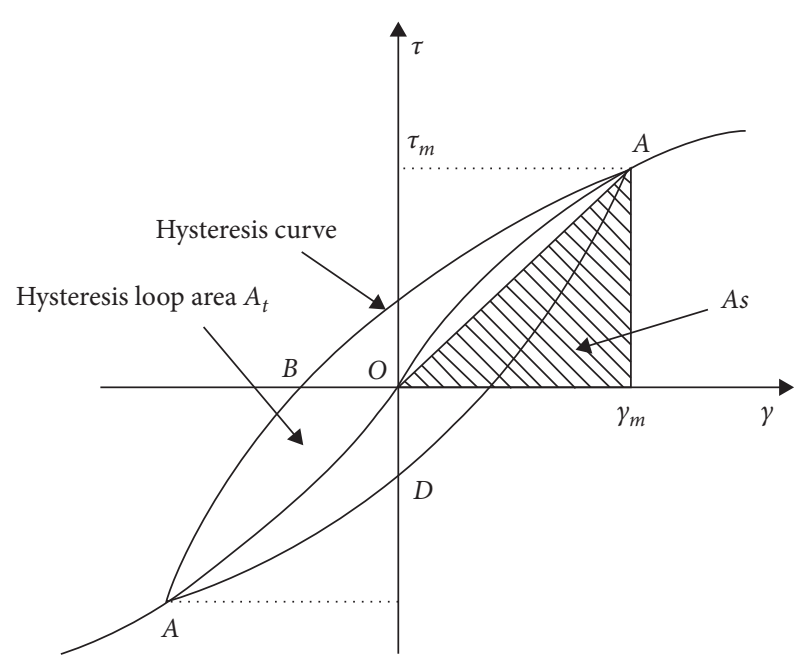

FIgURE 3: Typical stress-strain hysteresis curve.

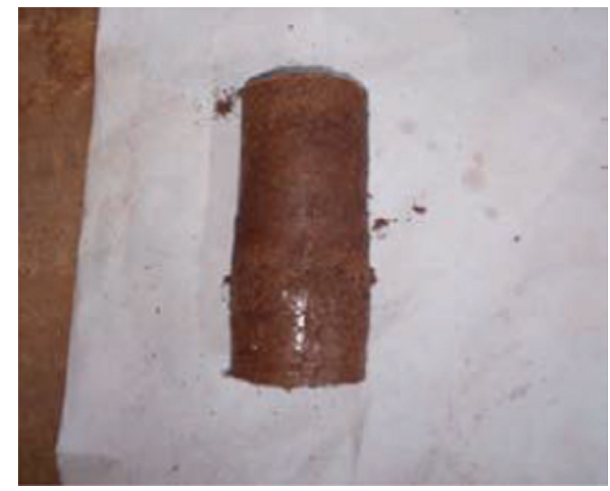

FIGURE 4: Bulging deformation.

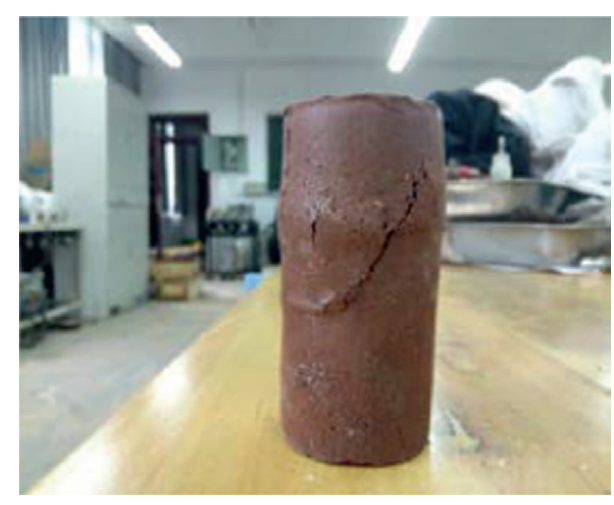

FIGURE 5: Shear failure.

4.3. Dynamic Shear Modulus. Figure 7 shows the dynamic shear modulus-shear strain curve of rubber-red clay mixture under different rubber powder content, different rubber powder particle size, different moisture contents, different compaction degrees, different confining pressures, and different vibration frequencies. Under different test conditions, the dynamic shear modulus-dynamic shear strain of rubber-soil shows the same attenuation law. When the shear strain is small, the attenuation is faster, the dynamic strain continues to increase, and the dynamic shear modulus basically tends to the same level. For an example, the curve of the mixture with rubber powder content is $6 \%$, the particle size is $0.85 \mathrm{~mm}$, the moisture content is $24.83 \%$, the degree of compaction is $90 \%$, the confining pressure is $100 \mathrm{kPa}$, and the vibration frequency is $1 \mathrm{~Hz}$ and was fitted using equation (4). The results are shown in Figure 8. From Figure 8, it can be seen that the test data can be well distributed on both sides of the model, and the degree of agreement is high enough. Therefore, equation (4) can be used to describe the relationship between the dynamic shear modulus and shear strain which is reasonable.

In Figure 7(a), the dynamic shear modulus decreases with an increase in rubber powder contents. For example, when the rubber powder content is $10 \%$, the maximum dynamic shear modulus of pure soil decreases from 33.7 MPa to $14.7 \mathrm{MPa}$ of rubber-red clay mixture, and the decrease rate was $56.4 \%$. The reason is that after rubber powder is added, the mechanical bite force between soil particles and rubber powder is significantly lower than that of plain soil. Under dynamic load, the deformation of the mixed soil increases, so the dynamic shear modulus decreases. In Figure 7(b), the dynamic shear modulus decreases with the increase in the rubber particle size. The reason is that the increase in the rubber particle size means that the particles become finer, and the specific surface area of the rubber increases. The contact area with the rubber particles increases, and the deformation of the mixed soil increases, so the dynamic shear modulus decreases. As shown in Figure $7(\mathrm{c})$, the dynamic shear modulus decreases with the increase in water content, which is due to the lubricating effect of water on the soil. With the increase in water content, the lubrication effect between soil particles becomes stronger; the larger the value was, the lower the dynamic shear modulus was. In Figures 7(d) and 7(e), the dynamic shear modulus increases with the increase in compaction and confining pressure. The mechanism of compaction and confining pressure was similar; that is, increasing compaction or confining pressure makes the soil particles compacted further, the ability of the soil to resist dynamic loads becomes stronger, and the dynamic shear modulus increases. In Figure 7(f), the dynamic shear modulus increases with the increase in vibration frequency. The reason is that the increase in vibration frequency reduces the action time of dynamic load on the soil, the soil is compacted in a very short time, the deformation reduced, and the dynamic shear modulus increased. However, the structure of the soil itself has not changed significantly, so the curve changes little.

\subsection{The Relationship between Damping Ratio and Dynamic} Shear Strain. Figure 9 shows the damping ratio-dynamic shear strain curve of mixed soil under different powder contents, different powder particle sizes, different moisture contents, different compaction degrees, different confining pressures, and different vibration frequencies. Both of the 

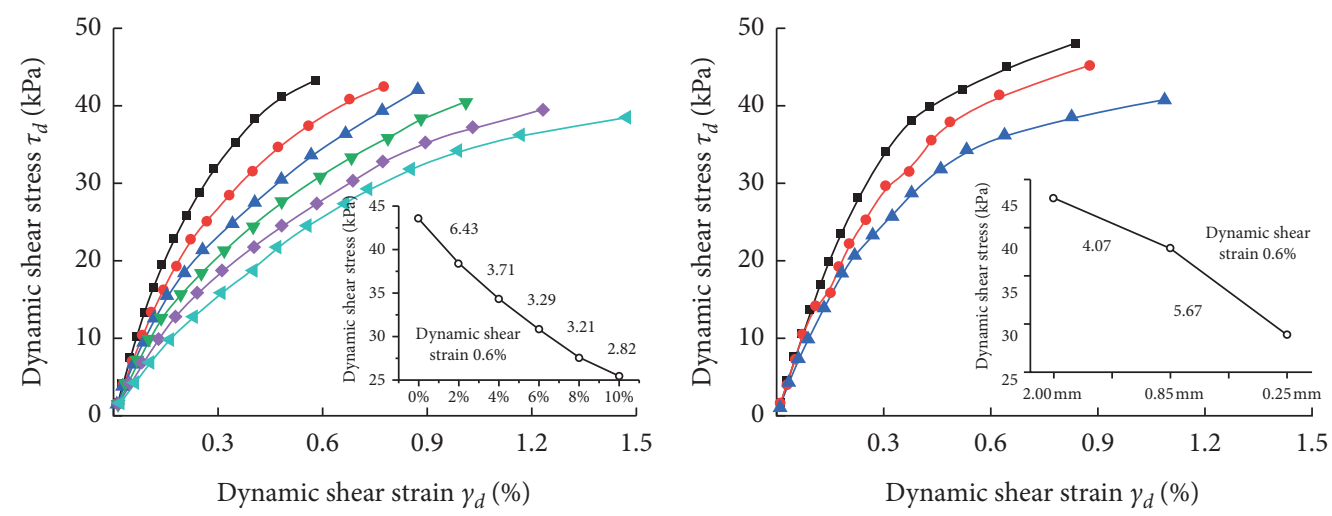

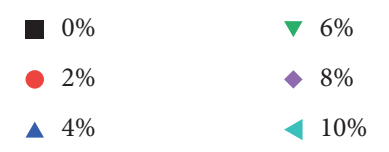

(a)

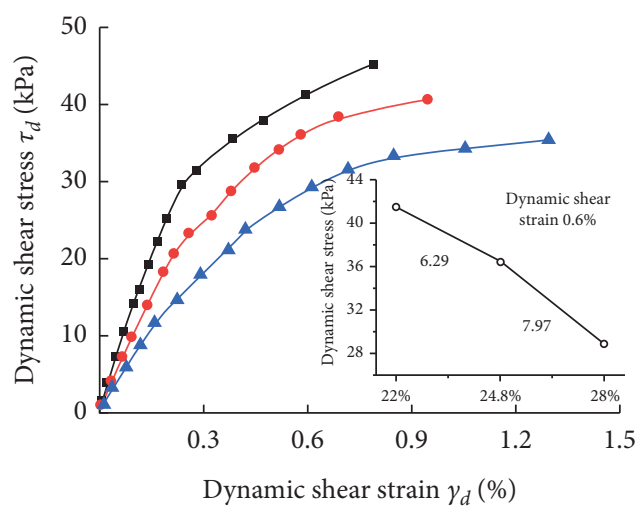

- $\omega=22 \%$

- $\omega=24.83 \%$

- $\omega=28 \%$

(c)

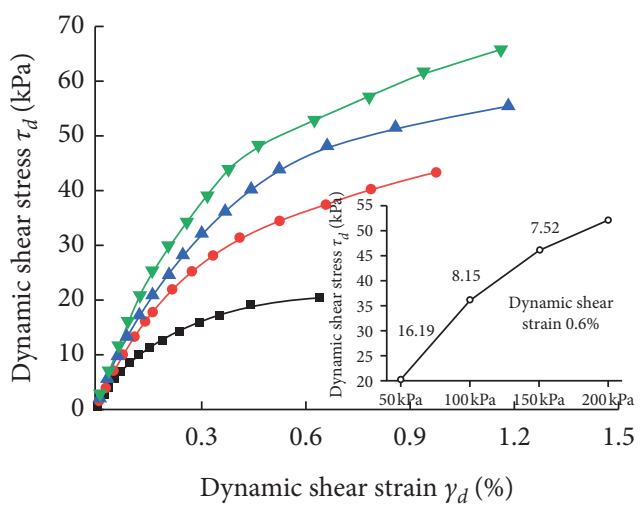

- $50 \mathrm{kPa}$

- $150 \mathrm{kPa}$

- $100 \mathrm{kPa}$

$\nabla 200 \mathrm{kPa}$

(e)
- $2.00 \mathrm{~mm}$
$0.85 \mathrm{~mm}$
A $0.25 \mathrm{~mm}$

(b)

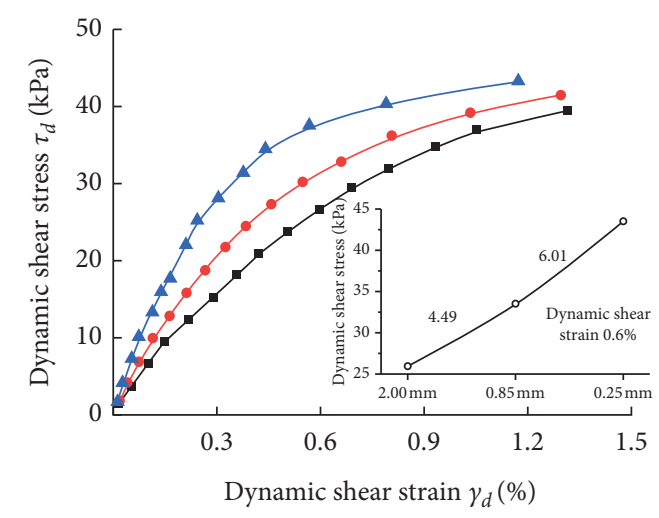

- $K=85 \%$

- $K=90 \%$

- $K=96 \%$

(d)

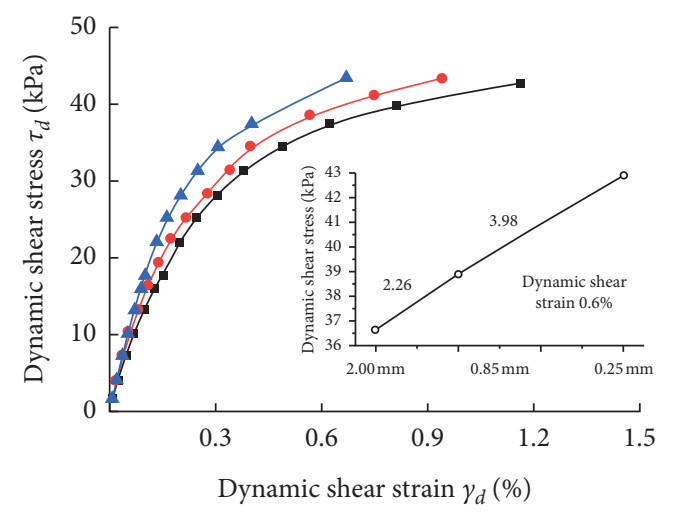

ㅁ $f=1 \mathrm{~Hz}$

- $f=2 \mathrm{~Hz}$

- $f=4 \mathrm{~Hz}$

(f)

FIGURE 6: Dynamic shear stress-shear strain curve of rubber-red clay. (a) Rubber powder content; (b) rubber particle size; (c) moisture content; (d) compactness; (e) confining pressure; (f) frequency. 

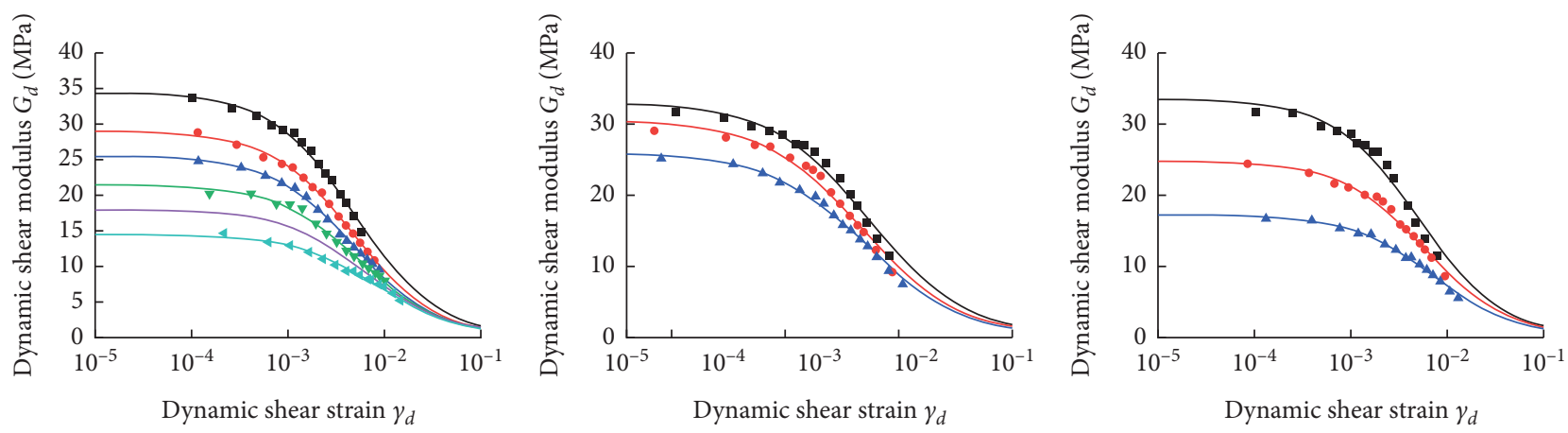

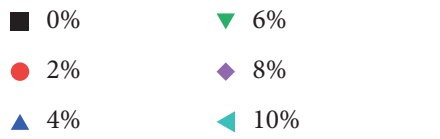

(a)

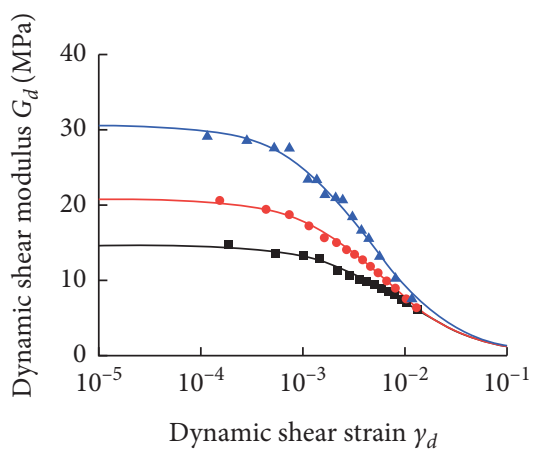

- $K=85 \%$

$K=90 \%$

А $K=96 \%$
$2.00 \mathrm{~mm}$

$0.85 \mathrm{~mm}$

A $0.25 \mathrm{~mm}$

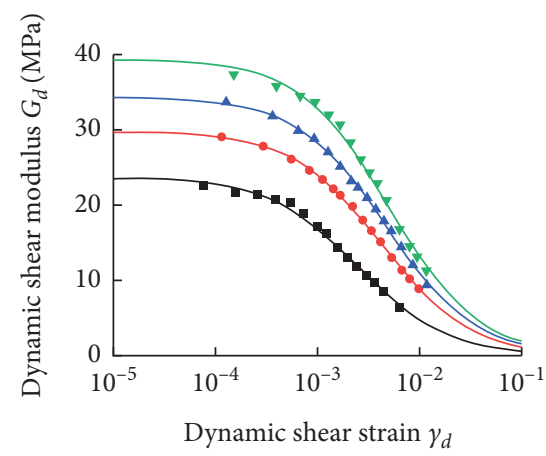

- $50 \mathrm{kPa}$

$100 \mathrm{kPa}$

- $150 \mathrm{kPa}$

$\nabla 200 \mathrm{kPa}$

(e)

- $\omega=22 \%$

- $\omega=24.83 \%$

- $\omega=28 \%$

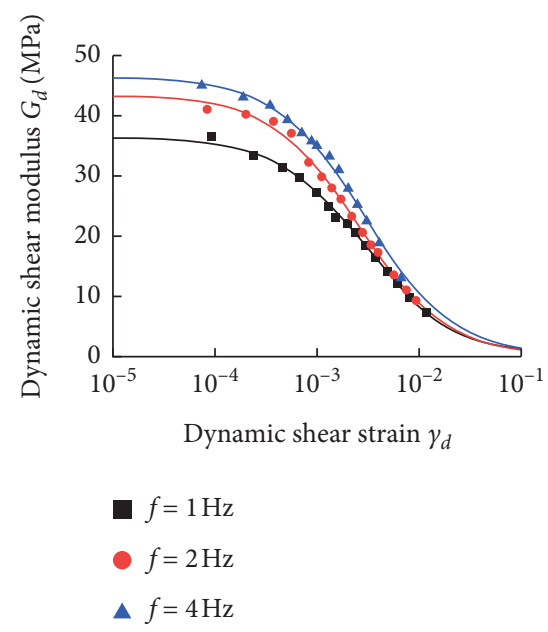

(f)

Figure 7: Dynamic shear modulus-dynamic shear strain curve of rubber-red clay. (a) Rubber powder content; (b) rubber particle size; (c) moisture content; (d) compactness; (e) confining pressure; (f) frequency.

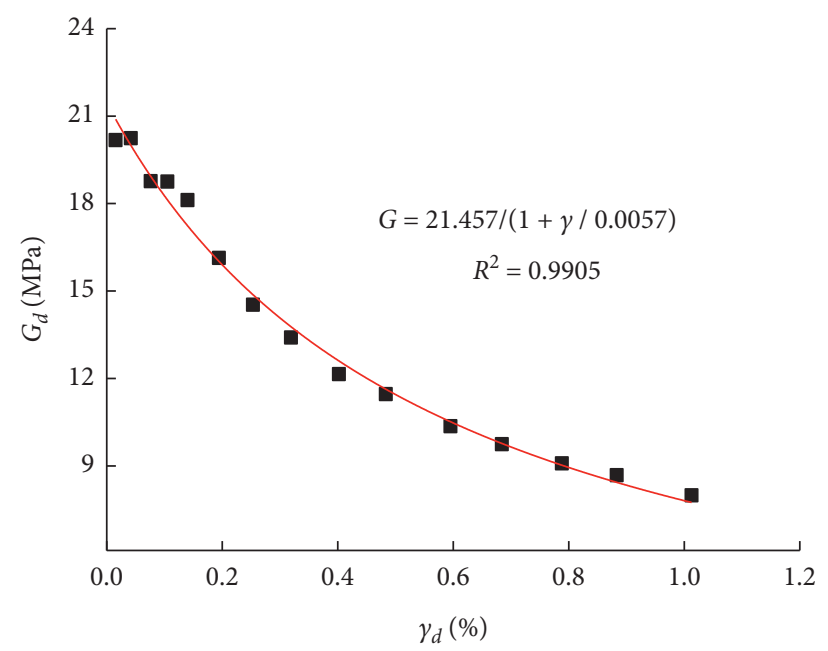

FIgURe 8: Typical dynamic shear modulus-shear strain curve fitting results. 


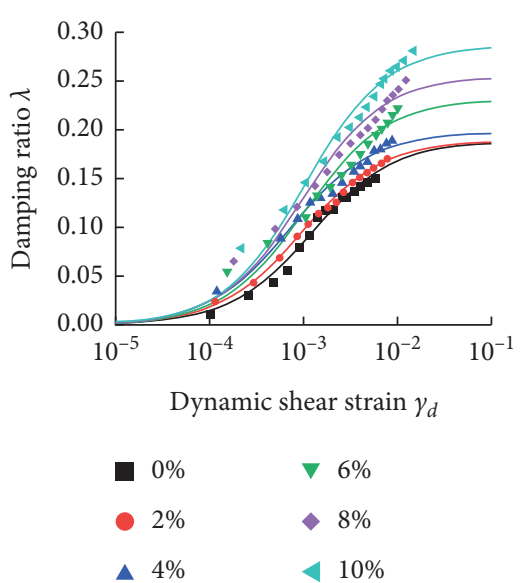

(a)

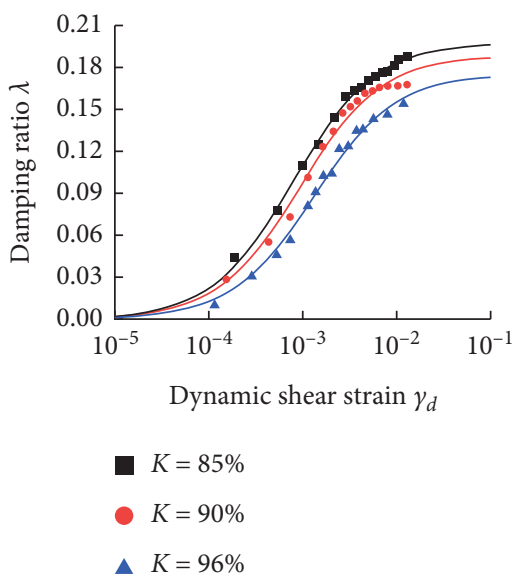

(d)

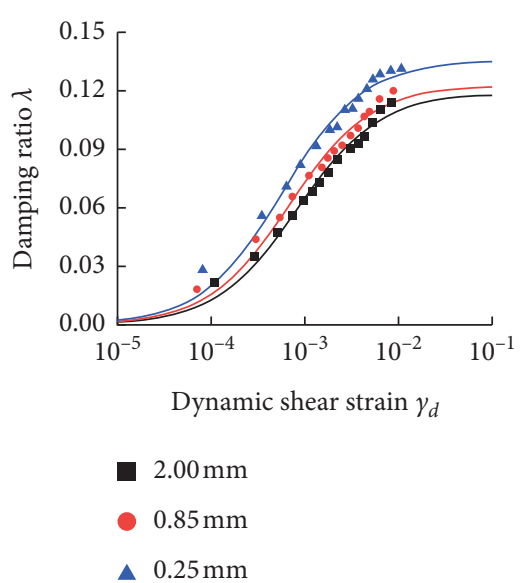

(b)

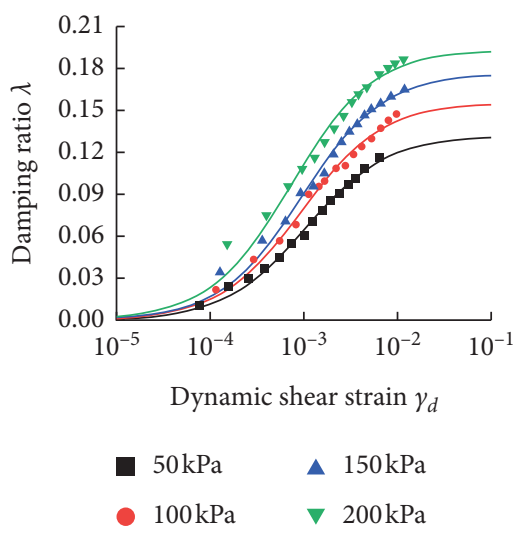

(e)

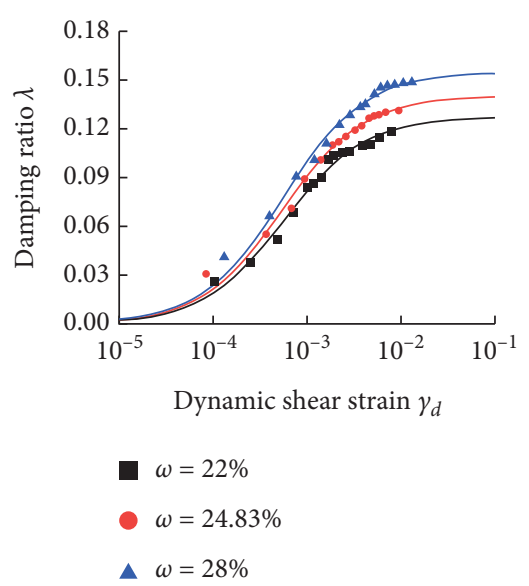

(c)

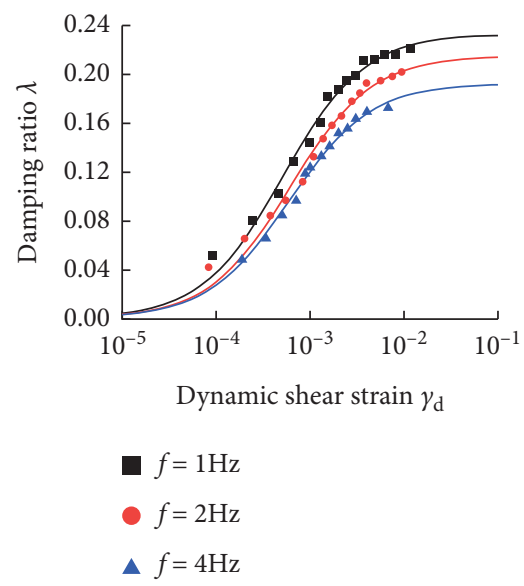

(f)

FiguRE 9: Rubber-red clay damping ratio and dynamic shear strain curve. (a) Rubber powder content; (b) rubber particle size; (c) moisture content; (d) compactness; (e) confining pressure; (f) frequency.

damping ratio of pure soil and mixtures increased with the increase in dynamic shear strain, and the nonlinear characteristic is strong. The curve of the mixture with the rubber powder content is $6 \%$, the particle size is $0.850 \mathrm{~mm}$, the water content is $24.83 \%$, the degree of compaction is $90 \%$, the confining pressure is $100 \mathrm{kPa}$, and the vibration frequency is $1 \mathrm{~Hz}$ and is fitted using equation (6). As presented in Figure 10 , the test data were in good agreement with the calculation model. Therefore, equation (7) can be used to describe the relationship between damping ratio and shear strain. The fitting curve under other test conditions is shown in Figure 9.

The damping ratio of the mixtures in Figure 9(a) increases with the increase in the rubber powder contents. The reason is that after the rubber powder is added, the soil becomes loose and the gap between the rubber powder and soil particles increases. As the density of the mixed soil becomes smaller, the energy loss when waves propagate in the mixed soil increases, so the damping ratio increases. In Figure 9(b), the damping ratio of the mixed soil increases with the decrease in the rubber particle size. The reason is that the rubber particle size becomes smaller and the contact area between the rubber and the soil particles becomes larger, and the energy consumed in the rubber is greater than the degree of soil consumption, so the damping ratio of the mixed soil increases. As shown in Figure 9(c), as the water content increases, the damping ratio of the mixed soil increases. The reason is that the energy transfer in the water consumes a lot of energy, so the damping ratio increases. As shown in Figures 9(d) and 9(e), as the degree of compaction and confining pressure increase, the damping ratio gradually decreases. Increasing the degree of compaction and confining pressure makes the soil more dense, and the energy is dissipated faster in the soil, so the damping ratio is reduced. As shown in Figure 9(f), the damping ratio decreases with the increase in the vibration frequency. When the vibration frequency increases, the action time of the dynamic load on the soil becomes shorter, the energy loss of the soil becomes smaller, the damping ratio decreases, and the damping ratio curve decreases gradually.

4.5. Mechanism Analysis. The research by Li et al. on dynamic characteristics of red clay based on the resonance column and dynamic triaxial tests shows that increasing soil compaction, confining pressure, consolidation ratio, and 


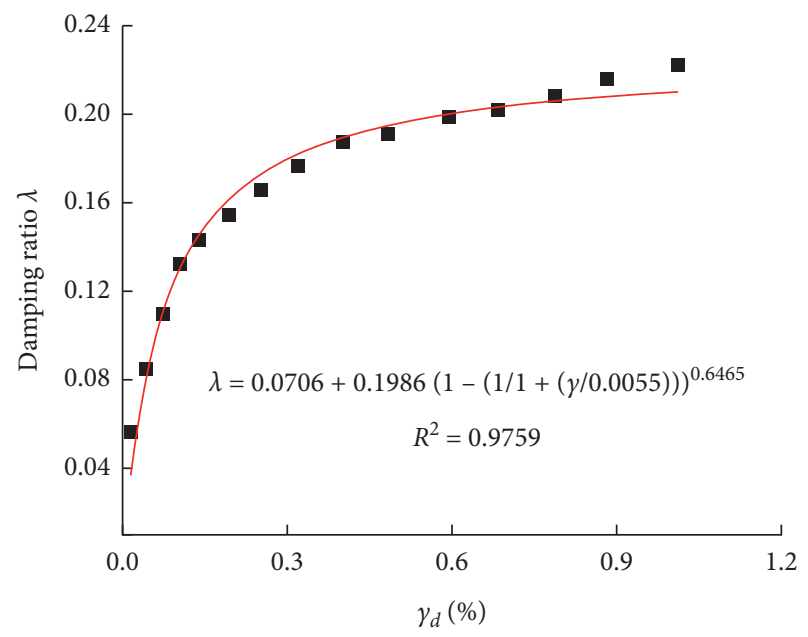

Figure 10: Typical dynamic shear modulus-shear strain curve fitting results.

vibration frequency will help improve dynamic strength and dynamic elastic modulus of soil. This paper concludes that the dynamic shear modulus of pure red clay is consistent with the previous literatures [31-34]; that is, with the increase in compaction, confining pressure, and vibration frequency, the dynamic shear modulus increases and the damping ratio decreases. With the increase in water content, the dynamic shear modulus decreases and the damping ratio increases.

The red clay has relatively fine particles and a large specific surface area. The particles have a strong interaction. When rubber is added into red clay, the original gradation of the red clay is changed, causing the pores between the particles increase. Therefore, under the action of dynamic load, it is easier to be compressed, and as the proportion of rubber increases, this effect becomes more obvious. In addition, after adding rubber particles to red clay, the content of hydrophilic minerals in the soil is reduced. At the same time, due to the surrounding effect of rubber particles on the soil particles, it hinders its interaction with water, so the strength of the mixed soil is reduced [35]. The rubber modulus is low, and it is easy to deform under compression. The addition of rubber accelerates the deformation of rubber-red clay mixture. Therefore, under different test conditions, the dynamic shear modulus of rubber-red clay decreases with the increase in rubber powder content, and the damping ratio increases with the increase in rubber powder content.

\section{Conclusions}

(1) There are two main failure types of rubber-red clay mixture in the test. When the rubber powder content is low or the soil moisture content is high, it shows bulging failure. When the rubber powder content is high or the water content is low, it shows the shear failure.

(2) With the increase in rubber powder content, the backbone curve of rubber-soil shows a downward trend. The dynamic shear modulus of rubber-red clay mixtures is greatly reduced compared with that of pure soil. Under different conditions, the rubber powder content increases and the dynamic shear modulus decreases and the damping ratio increases, and with the increase in rubber content, the nonlinear characteristics of the dynamic shear modulus and dynamic shear strain curve weaken. The backbone curve and the Hardin-Drnevich model of dynamic shear modulus attenuation indicate that the damping ratio can be described by the modified Chen et al. model.

(3) With the increase in the rubber particle size, the dynamic shear modulus decreases and the damping ratio increases. Because the larger rubber particles have better shear properties for the mixture, the larger rubber particle can be considered in the test. Increasing the water content of the mixture will reduce the dynamic shear modulus of the soil and increase the damping ratio. The backbone curve, the shear modulus-shear strain curve, and the damping ratio-shear strain curve are negatively correlated with the water content and are related to the rubber particle size. The diameter and damping ratio are positively correlated.

(4) Under the same test conditions, when the degree of compaction and confining pressure increase, the dynamic shear modulus of rubber soil will increase, the damping ratio will decrease, and the backbone curve will move down. When the loading frequency increases, the dynamic shear modulus will increase and the damping ratio will decrease, but the change is not significant.

(5) Adding rubber to red clay can significantly reduce the dynamic shear modulus of red clay and increase its damping ratio, indicating that rubber-red clay has smaller shear stiffness and larger damping. In addition, its optimal moisture content does not change much, and it can be used as roadbed foundation and roadbed seismic isolation material. 


\section{Data Availability}

The data used to support the findings of this study are available from the corresponding author upon request.

\section{Conflicts of Interest}

The authors declare that they have no conflicts of interest regarding the publication of this paper.

\section{Acknowledgments}

This research was funded by the National Natural Science Foundation of China (grant nos. 51368010 and 51680011), Guizhou Provincial Science and Technology Support Plan Project (grant no. Qianke Science Support [2016] 2005), and Guizhou Provincial Department of Science and TechnologyGuizhou University Joint Fund Project (grant no. Qiankehe LH [2014] 7663).

\section{References}

[1] M. Záleská, Z. Pavlík, D. Čítek, O. Jankovský, and M. Pavlíková, "Eco-friendly concrete with scrap-tyre-rubberbased aggregate-properties and thermal stability," Construction And Building Materials, vol. 225, pp. 709-722, 2019.

[2] A. Soltani, A. Deng, A. Taheri, and A. Sridharan, "Swellshrink-consolidation behavior of rubber-reinforced expansive soils," Geotechnical Testing Journal, vol. 42, no. 3, pp. 761-788, 2019.

[3] T. M. Pham, W. Chen, A. M. Khan, H. Hao, M. Elchalakani, and T. M. Tran, "Dynamic compressive properties of lightweight rubberized concrete," Construction and Building Materials, vol. 238, 2020.

[4] S. S. Narani, M. Abbaspour, S. M. Mir Mohammad Hosseini, E. Aflaki, and F. Moghadas Nejad, "Sustainable reuse of waste tire textile fibers (WTTFs) as reinforcement materials for expansive soils: with a special focus on landfill liners/covers," Journal of Cleaner Production, vol. 247, 2020.

[5] J. Mo, L. Zeng, Y. Liu et al., "Mechanical properties and damping capacity of polypropylene fiber reinforced concrete modified by rubber powder," Construction And Building Materials, vol. 242, 2020.

[6] L. Liu, G. Cai, J. Zhang, X. Liu, and K. Liu, "Evaluation of engineering properties and environmental effect of recycled waste tire-sand/soil in geotechnical engineering: a compressive review," Renewable and Sustainable Energy Reviews, vol. 126, 2020.

[7] C. Fang, N. Guo, Z. You, and Y. Tan, "Investigating fatigue life prediction of rubber asphalt mixture based on damage evolution using residual strain analysis approach," Construction and Building Materials, vol. 257, 2020.

[8] M. Bekhiti, H. Trouzine, and M. Rabehi, "Influence of waste tire rubber fibers on swelling behavior, unconfined compressive strength and ductility of cement stabilized bentonite clay soil," Construction And Building Materials, vol. 208, pp. 304-313, 2019.

[9] A. O. Adeboje, W. K. Kupolati, E. R. Sadiku, J. M. Ndambuki, and C. Kambole, "Experimental investigation of modified bentonite clay-crumb rubber concrete," Construction And Building Materials, vol. 233, 2020.

[10] E. Abd-Elaal, S. Araby, J. E. Mills et al., "Novel approach to improve crumb rubber concrete strength using thermal treatment," Construction and Building Materials, vol. 229, 2019.

[11] B. Tiwari, B. Ajmera, S. Moubayed, A. Lemmon, and K. Styler, Soil Modification with Shredded Rubber Tires, GeoCongress, Oakland, California, 2012.

[12] Z. H. Li and H. Y. Zhang, "Compaction properties of granulated rubber and loess mixtures," Rock and Soil Mechanics, vol. 31, no. 12, pp. 3715-3720, 2010.

[13] N. Tatlisoz, C. H. Benson, and T. B. Edil, "Effect of fines on mechanical properties of soil-tire chip mixtures," Testing Soil Mixed with Waste or Recycled Materials, pp. 93-108, American Society for Testing and Materials, New Orleans, LA, USA, 1997.

[14] D. V. Okur and S. U. Umu, "Dynamic properties of clean sand modified with granulated rubber," Advances in Civil Engineering, vol. 2018, Article ID 5209494, 11 pages, 2018.

[15] O. Gunaydin, H. Cetin, and M. Fener, "Geotechnical properties of tire-cohesive clayey soil mixtures as a fill material," Engineering Geology, vol. 88, no. 1/2, pp. 110-120, 2006.

[16] R. C. Chaney, K. R. Demars, Z. Feng, and K. G. Sutter, "Dynamic properties of granulated rubber/sand mixtures," Geotechnical Testing Journal, vol. 23, no. 3, pp. 338-344, 2000.

[17] B. Li, M. Huang, and X. Zeng, "Dynamic behavior and liquefaction analysis of recycled-rubber sand mixtures," Journal of Materials In Civil Engineering, vol. 28, 2016.

[18] K. Senetakis and A. Anastasiadis, "Effects of state of test sample, specimen geometry and sample preparation on dynamic properties of rubber-sand mixtures," Geosynthetics International, vol. 22, no. 4, pp. 301-310, 2015.

[19] A. Anastasiadis, K. Senetakis, and K. Pitilakis, "Small-strain shear modulus and damping ratio of sand-rubber and gravelrubber mixtures," Geotechnical and Geological Engineering, vol. 30, no. 2, pp. 363-382, 2012.

[20] S. S. Kermani, S. M. Marandi, A. Nakhaei, and M. H. Bagheripour, "Dynamic properties of granular soils mixed with granulated rubber," Soil Dynamics And Earthquake Engineering, vol. 43, no. 2, pp. 124-132, 2012.

[21] S. P. Shang, X. X. Sui, Z. J. Zhou, F. C. Liu, and X. W. Wang, "Study of dynamic shear modulus of granulated rubbers and mixture," Rock and Soil Mechanics, vol. 31, no. 2, pp. 377-381, 2010.

[22] F. C. Liu, L. W. Chen, and D. Hai, "Evaluation of dynamic shear modulus and damping ratio of rubber-sand mixture based on cyclic simple shear tests," Rock and Soil Mechanics, vol. 37, no. 7, pp. 1903-1913, 2016.

[23] L. H. Li, H. L. Xiao, H. M. Tang, Q. Z. Hu, M. J. Sun, and L. Sun, "Dynamic properties variation of tire shred-soil mixtures," Rock and Soil Mechanics, vol. 35, no. 2, pp. 359364, 2014

[24] Z. P. Hu, Z. H. Liu, Z. Q. Zhang, W. W. Xu, and X. B. Yan, "Experiment of the influence of rubber powder on dynamic characteristics of remolded loess," Journal of Chang'an University (Natural Science Edition), vol. 33, no. 4, pp. 62-67, 2013.

[25] B. O. Hardin and V. P. Drnevich, "Shear modulus and damping of soils: measurement and parameter effects," Journal of Soil Mechanics and Foundation Division, vol. 9, no. 2, 1973.

[26] K. H. Stokoe, M. B. Darendeli, R. D. Andrus, and L. T. Brown, "Dynamic soil properties: laboratory, field and correlation studies," in Proceedings of the 2nd International Conference on Earthquake Geotechnical Engineering, vol. 3, pp. 811-845, Lisbon, 1999. 
[27] P. P. Martin and H. B. Seed, "One-dimensional dynamic ground response analyses," Journal of the Geotechnical Engineering Division, vol. 108, pp. 935-952, 1982.

[28] H. B. Roy, "Dynamic properties of piedmont residual soils," Journal of Geotechnical Engineering, ASCE, vol. 122, pp. 813-821, 1996.

[29] S. M. Wu, Soil Dynamics, Construction Industry Press, Beijing China, 2000.

[30] G. X. Chen, X. Z. Liu, D. H. Zhu, and Q. X. Hu, "Experimental studies on dynamic shear modulus ratio and damping ratio of recently deposited soils in Nanjing," Chinese Journal of Geotechnical Engineering, vol. 28, no. 8, pp. 1023-1027, 2006.

[31] J. Li, S. X. Chen, L. F. Jiang, and S. D. Xiong, "Experimental study on influence of stress history on dynamic characteristics of remolded red clay," Journal of Geotechnical Engineering, vol. 36, no. 9, pp. 1657-1665, 2014.

[32] J. Li, S. X. Chen, L. F. Jiang, and S. D. Xiong, "Resonance column test of dynamic shear modulus and damping ratio of remolded red clay," Journal of Sichuan University (Engineering Science Edition), vol. 45, no. 4, pp. 62-68, 2013.

[33] Z. Zhang, Y. Chen, G. Ye, P. Xiang, Y. Xiao, and Q. Wang, "Empirical method for evaluating resilient modulus of saturated silty clay under cyclic loading," Advances in Civil Engineering, vol. 2020, Article ID 8846895, 12 pages, 2020.

[34] H. Lei, S. Feng, R. Jia, and M. Jiang, "Experimental investigation of the deformation characteristics of tianjin clays under coupled dynamic stress and seepage fields," Advances in Civil Engineering, vol. 2019, Article ID 3785937, 14 pages, 2019.

[35] W. L. Zou, P. Xie, Q. T. Ma, W. Yang, and C. Y. Zuo, "Experimental study on modified expansive soil of rubber particles in waste tire," Journal of Sichuan University (Engineering Science Edition), vol. 43, no. 3, pp. 44-48, 2011. 